\title{
Fetal hydrops
}

\author{
P A Boyd, J W Keeling
}

\begin{abstract}
Seventy-two fetuses or neonates with non-immune hydrops were examined between 1983 and 1988. The commonest association was chromosome abnormality; 11 fetuses had a 45,X karyotype and 11 autosomal trisomy. Chromosome abnormality was suspected in a further 20 on necropsy findings but chromosome culture was not possible or unsuccessful. In 11 cases there was histological evidence of infection; seven babies had major structural anomalies and six affected fetuses were twins. In six $(8 \%)$ the cause of hydrops was not determined compared with eight $(16 \%)$ of cases examined between 1976 and 1982. Hydrops was diagnosed more frequently while the fetus was alive, before 20 weeks' gestation, and associated with chromosome anomaly than found previously.
\end{abstract}

Effective prevention of rhesus disease has shifted the emphasis of the investigation of the pregnancy complicated by fetal hydrops towards non-immunological causes. ${ }^{1}$ The increasing availability of obstetric ultrasound and its use in the investigation of pregnancies which are 'large for dates' or have a clinical diagnosis of polyhydramnios has resulted in a larger proportion of cases of fetal hydrops being diagnosed while the fetus is still alive. The more frequent use of ultrasound for dating purposes in the second trimester, together with opportunities for a detailed fetal anomaly scan around 20 weeks' gestation, means that many hydropic fetuses are now recognised at an asymptomatic stage. This enables a wider range of investigations to be undertaken. Elucidation of the underlying cause or association of hydrops should be possible in a larger proportion of cases.

We report our experience with fetal hydrops during the last five years and compare gestational age at diagnosis, method of diagnosis, and pathological findings in the hydropic fetus with those examined in the same unit between 1976 and $1982 .^{2}$

\section{Material and methods}

Cases of fetal hydrops from pregnancies which terminated in both the second and third trimesters were identified from the files of the Department of Paediatric Pathology, John Radcliffe Maternity Hospital (JRH), Oxford. These comprised fetuses from women who were booked for delivery at that hospital and those referred for pathological examination. Referral was often prompted by prenatal investigations undertaken in Oxford, either ultrasound examination at the JRH or through the Department of Medical Genetics.

Fetal hydrops was defined as generalised subcutaneous oedema with an effusion in at least one body cavity. After pathological examination each case was allotted to one of six groups: proven chromosome anomaly, dysmorphic features (two or more) suggestive of chromosome anomaly but without cytogenetic diagnosis, infection, visceral anomaly, complication of twin pregnancy, and idiopathic. Clinical and pathological details were considered first within each group and then the groups were compared with each other. They were finally compared with cases of fetal hydrops seen between 1976 and 1982 .

\section{Results}

Pertinent clinical details of each pregnancy and the results of prenatal ultrasound examination and chromosome culture are presented in table 1, grouped according to pathological findings in the fetus. A comparison between the groups is made in table 2 and gestational age at diagnosis, status at delivery, and pathological associations are compared with cases reported previously in table 3 .

\section{CHROMOSOME ANOMALY}

The commonest association of fetal hydrops seen during the present study was chromosome anomaly. There were 22 such fetuses (table 1). The hydropic state in all fetuses in this group was identified by ultrasound scan. In seven this was during a scan before amniocentesis. Amniocentesis was indicated because of advanced maternal age in six and for known maternal balanced translocation in one case. In 13 of the remaining 15 women, a hydropic fetus was identified on routine scan, and in two women a detailed scan was performed because of raised maternal serum alphafetoprotein level and a history of intrauterine growth retardation, respectively.

Half of the fetuses with chromosome anomaly exhibited a 45,X karyotype. In 10 of the 11 , postnuchal fluid accumulation was described in the scan report and two were already dead when the scan took place. Examination of these fetuses after delivery showed that 10 out of 11 exhibited tubular hypoplasia of the distal aortic arch (Haa). In case 11 , material was not available for review. The only other cardiac anomaly was a persistent left superior vena cava (PLSVC). Three fetuses had horseshoe kidney and a further fetus had unilateral incomplete renal rotation, the renal pelvis facing anteriorly.

Three of five fetuses with trisomy 21 had cardiovascular malformations. These were 
Table 1 Clinical details of pregnancies complicated by fetal hydrops.

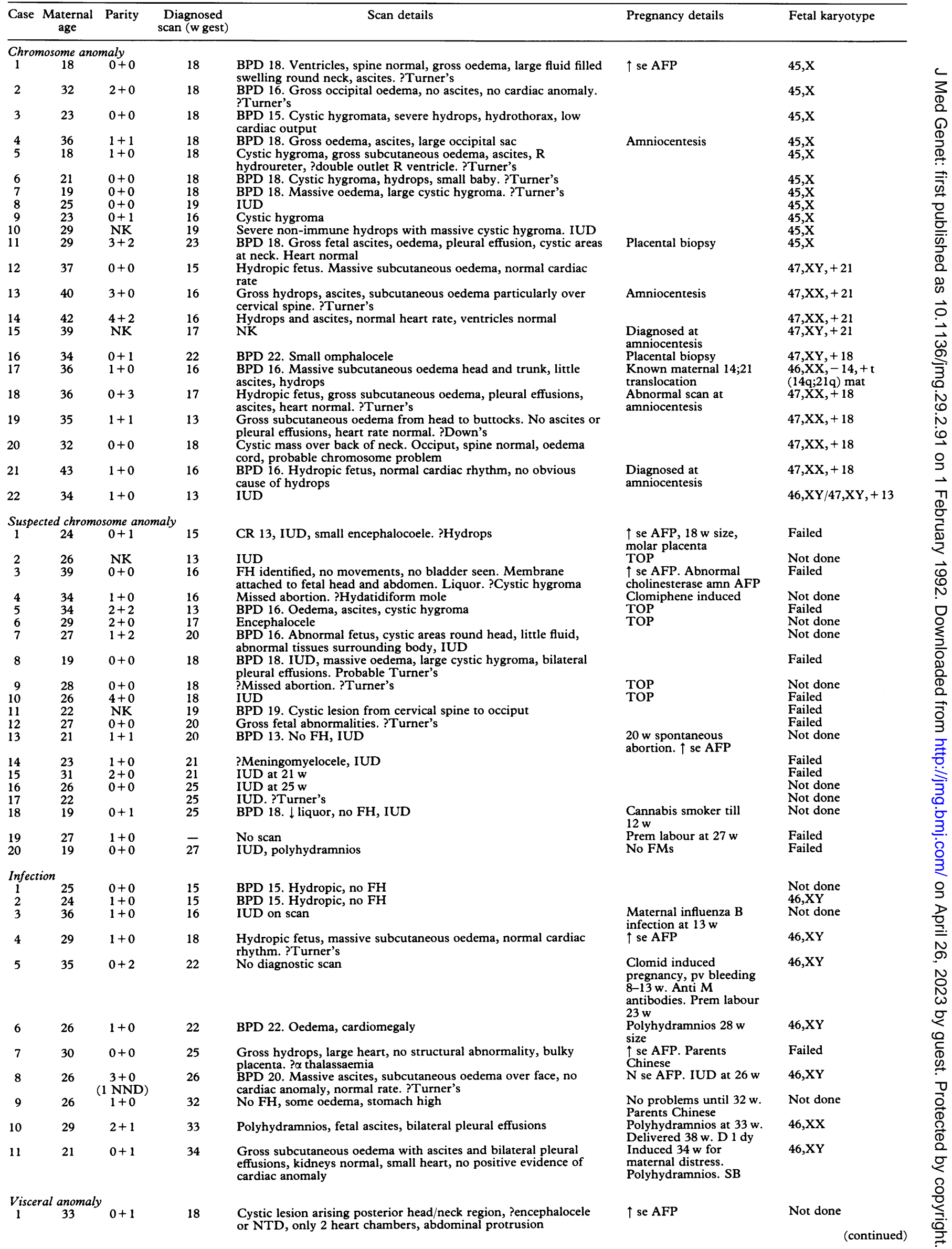




\begin{tabular}{|c|c|c|c|c|c|c|}
\hline Case & $\begin{array}{l}\text { Maternal } \\
\text { age }\end{array}$ & Parity & $\begin{array}{l}\text { Diagnosed } \\
\text { scan (w gest) }\end{array}$ & Scan details & Pregnancy details & Fetal karyotype \\
\hline 2 & 19 & $0+1$ & 25 & Gross hydrops, grossly abnormal fetus & $\begin{array}{l}\text { Threatened abortion } \\
25 \mathrm{w} \text {. Delivered } 27 \mathrm{w}\end{array}$ & $46, X Y$ \\
\hline 3 & 29 & $0+0$ & 25 & $\begin{array}{l}\text { BPD } 25 . \text { Hydropic fetus with enlarged heart, normal rhythm, } \\
\text { right ventricle small, ascites, subcutaneous oedema }\end{array}$ & $\begin{array}{l}30 \mathrm{w} \text { size at } 24 \mathrm{w} \text {. } \\
\text { Placental biopsy }\end{array}$ & $46, \mathrm{XX}$ \\
\hline 4 & 29 & $0+1$ & 27 & $\begin{array}{l}\text { BPD 27. Polyhydramnios, heart normal, abdominal distension, } \\
\text { ?cystic structure, ascites, no oedema, normal placenta }\end{array}$ & $\begin{array}{l}\text { Polyhydramnios } \\
\text { APH } 27 \mathrm{w}\end{array}$ & $46, X Y$ \\
\hline 5 & 29 & $1+0$ & & No scan & $\begin{array}{l}\text { APH } 27 \mathrm{w} \text {. Preterm } \\
\text { labour CS. Hydropic } \\
\text { male }\end{array}$ & Not done \\
\hline 6 & 24 & $0+1$ & 28 & Breech. Irregular heart rhythm, gross hydramnios & $\begin{array}{l}\text { Pregnancy telangectasia. } \\
\text { Polyhydramnios. } \\
\text { SB } 29 \mathrm{w}\end{array}$ & $46, \mathrm{XX}$ \\
\hline 7 & 22 & $0+0$ & 31 & $\begin{array}{l}\text { Abnormal brain with dilated ventricle, soft tissue mass. } \\
\text { ?haematoma, hydrops, pericardial effusion }\end{array}$ & $\begin{array}{l}37 \mathrm{w} \text { size at } 31 \mathrm{w} \\
\text { Proteinuria }++\end{array}$ & $46, \mathrm{XX}$ \\
\hline \multicolumn{7}{|c|}{ 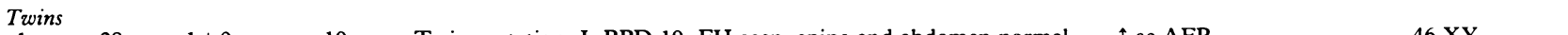 } \\
\hline 1 & 28 & $1+0$ & 19 & $\begin{array}{l}\text { Twin gestation. I. BPD 19. FH seen, spine and abdomen normal. } \\
\text { II. No FH, grossly hydropic. BDP } 12 \text {. No membrane between } \\
\text { fetuses. }\end{array}$ & $\begin{array}{l}\uparrow \text { se AFP } \\
\text { Placental biopsy. I } \\
\text { normal male, delivered } \\
36 \mathrm{w}\end{array}$ & $46, X Y$ \\
\hline 2 & 27 & $2+0$ & 23 & Polyhydramnios & $\begin{array}{l}\text { I. } \mathrm{d} 1 \mathrm{~h} \text {, hydropic } \\
\text { II. IUD } 10 \mathrm{dy} \text { before } \\
\text { delivery at } 31 \mathrm{w}\end{array}$ & I $46, \mathrm{XX}$ \\
\hline 3 & 36 & $1+1$ & 26 & Hydrops in 1 twin only, ascites & $\begin{array}{l}\text { Polyhydramnios } \\
\text { Prem labour, deliv } 26 \mathrm{w} \text {. } \\
\text { I hydropic d } 40 \mathrm{~h} \text {. II d } \\
5 \text { dy. IVH }\end{array}$ & I $46, \mathrm{XX}$ \\
\hline 4 & 25 & $0+0$ & 27 & $\begin{array}{l}\text { I. Massive hydrops, ascites, distended bladder, hydrocalyces, no } \\
\text { other structural anomaly. II. Squashed }\end{array}$ & $\begin{array}{l}\text { Thr abortion following } \\
\text { amnio. I. SB hydropic. } \\
\text { II. d } 10 \text { dy }\end{array}$ & Not done \\
\hline 5 & 27 & $1+0$ & 19 & Twins. One twin omphalocele or gastroschisis, gut only & $\begin{array}{l}\text { Prem labour, } \mathrm{APH} \text { at } \\
32 \mathrm{w}\end{array}$ & $\begin{array}{l}46, X Y \\
46, X Y\end{array}$ \\
\hline 6 & 24 & $1+1$ & 32 & $\begin{array}{l}\text { I hydropic, II omphalocele. IUD } \\
\text { No diagnostic scan }\end{array}$ & $\begin{array}{l}\text { Spont lab } 39 \mathrm{w} \text {, ?IUD } 1 \\
\text { week previously. I } \\
\text { survived }\end{array}$ & ?I $46, \mathrm{XX}$ \\
\hline \multicolumn{7}{|c|}{ Idiopathic } \\
\hline $\begin{array}{l}1 \\
2\end{array}$ & $\begin{array}{l}26 \\
31\end{array}$ & $\begin{array}{l}3+1 \\
2+0\end{array}$ & $\begin{array}{l}16 \\
17\end{array}$ & $\begin{array}{l}\text { Large cystic spaces in neck, bilateral pleural effusions } \\
\text { Moderate bilateral pleural effusions, subcutaneous oedema over } \\
\text { scalp and trunk, cardiac rate normal }\end{array}$ & $\begin{array}{l}\text { Amniocentesis } \\
\text { Placental biopsy }\end{array}$ & $\begin{array}{l}46, X Y \\
46, X Y\end{array}$ \\
\hline $\begin{array}{l}3 \\
4\end{array}$ & $\begin{array}{l}24 \\
36\end{array}$ & $\begin{array}{l}1+0 \\
0+2\end{array}$ & $\begin{array}{l}20 \\
24\end{array}$ & $\begin{array}{l}\text { Hydrops. ?Pelvic teratoma } \\
\text { BPD 20. No FH }\end{array}$ & $\begin{array}{l}\text { IUD at } 20 \mathrm{w} \\
\text { Pergonal induced } \\
\text { pregnancy }\end{array}$ & $\begin{array}{l}\text { Failed } \\
46, \mathrm{XX}\end{array}$ \\
\hline 5 & 38 & $2+1$ & 32 & No FH. Massive pleural effusions, ascites, hydrops & $\begin{array}{l}\text { Maternal age amnio, SB } \\
\text { at } 32 \mathrm{w}\end{array}$ & $46, X Y$ \\
\hline 6 & 26 & $1+0$ & 33 & $\begin{array}{l}\text { Head too low to measure, large amount of fluid in chest, thick } \\
\text { layer over abdomen }\end{array}$ & $\begin{array}{l}\text { Hydramnios at } 33 \mathrm{w} \text {, } \\
\text { term size. Live born. } \\
\text { Survived, mild mental \& } \\
\text { motor delay }\end{array}$ & $46, \mathrm{XX}$ \\
\hline
\end{tabular}

$\mathrm{BPD}(18)=$ biparietal diameter equivalent to (18) weeks gestation.

IUD $=$ intrauterine death .

$\mathrm{NK}=$ not known.

$\mathbf{w}=$ weeks' gestation

$\mathrm{d}=$ died.

se $\mathrm{AFP}=$ serum alphafetoprotein.

FMs $=$ fetal movements.

$\mathrm{FH}=$ fetal heart.

CR13 = crown-rump measurement equivalent to 13 weeks' gestation.

ventricular septal defect (VSD), VSD plus $\mathrm{Haa}$, and Haa in addition to external dysmorphic features. Three of five fetuses with trisomy 18 karyotype also had cardiac defects (atrial septal defect plus VSD, VSD plus Haa, and Haa plus aberrant right subclavian artery). The mosaic trisomy 13 fetus exhibited many dysmorphic features including cleft lip and palate; the heart had a globular appearance but normal anatomy, a finding in trisomy 13 at term. Eight out of 22 of the women whose hydropic fetus had a chromosome anomaly have achieved one or more subsequent successful pregnancies.
SUSPECTED CHROMOSOME ANOMALY

There were 20 fetuses where necropsy showed two or more anomalies suggestive of an abnormal karyotype but where tissue culture for chromosome analysis was either unsuccessful or not possible because the fetus was received after fixation. Hydrops was found on ultrasound examination in 19 of 20 cases during the second trimester. Eight scans were undertaken for a variety of clinical reasons, three because of raised maternal serum alphafetoprotein (AFP) levels, and hydrops was detected during a routine scan in eight women. Thirteen of these fetuses were dead at the time of diagnosis

Table 2 Clinical details of hydropic pregnancies. Comparison between different diagnostic groups.

\begin{tabular}{lcccccc}
\hline Pathological diagnosis & $\begin{array}{c}\text { Chromosome } \\
\text { anomaly }\end{array}$ & $\begin{array}{c}\text { Suspected } \\
\text { chromosome } \\
\text { anomaly }\end{array}$ & Infection & $\begin{array}{c}\text { Visceral } \\
\text { anomaly }\end{array}$ & Twin & Idiopathic \\
\hline No of cases & 22 & 20 & 11 & 7 & 6 & 6 \\
Mean maternal age (y) (SD) & $31(8)$ & $26(5)$ & $28(5)$ & $26(5)$ & $25(4)$ & $30(5)$ \\
Mean (SD) gestation at & $17(3)$ & $19(4)$ & $24(7)$ & $26(5)$ & $23(4)$ & $24(7)$ \\
diagnostic scan (w) & $(\mathrm{n}=20)$ & $(\mathrm{n}=19)$ & $(\mathrm{n}=10)$ & $(\mathrm{n}=5)$ & $(\mathrm{n}=5)$ & $(\mathrm{n}=6)$ \\
Chromosome analysis & $0 / 22 / 0$ & $0 / 0 / 20$ & $5 / 0 / 6$ & $5 / 0 / 2$ & $3 / 0 / 3$ \\
normal/abnormal/failed & & & & & & \\
\hline
\end{tabular}


Table 3 Comparison between previously reported cases from this centre and present series.

\begin{tabular}{lll}
\hline Period seen & $1976-82^{2}$ & $1983-87$ \\
\hline No & 50 & 72 \\
Before 21 w & 3 & 41 \\
$\quad 21-27 \mathrm{w}$ & 16 & 22 \\
$\quad 28 \mathrm{w}$ to term & 31 & 9 \\
Abortus & 19 & 56 \\
Stillbirth & 18 & 9 \\
Live birth (survival) & $13(3)$ & $7(1)$ \\
$\begin{array}{l}\text { Diagnosis after path } \\
\text { examination }\end{array}$ & $42(84 \%)$ & $66(92 \%)$ \\
$\quad \begin{array}{l}\text { Chromosome anomaly } \\
\text { diagnosed }\end{array}$ & 5 & 22 \\
$\quad$ Chromosome anomaly & 5 & 20 \\
$\quad$ suspected & 3 & 11 \\
$\quad$ Infection & 8 & 7 \\
$\quad$ Tisceral anomaly & 23 & 6 \\
$\quad$ Other & 1 & $6(8.0 \%)$ \\
Idiopathic & $8(16 \%)$ & \\
\hline
\end{tabular}

which in part explains failure of cytogenetic analysis.

There was very prominent postnuchal fluid accumulation in addition to generalised hydrops and effusion in body cavities in 17 of the 20 fetuses in this group; this had been noted on scan in six cases. In 12 of the 17, the distal aortic arch was hypoplastic and six had another cardiovascular anomaly (bicuspid aortic valve, PLSVC plus aberrant right subclavian artery, PLSVC plus single umbilical artery, bicuspid aortic valve plus PLSVC, single coronary origin, and atrioventricular canal defect). Two further fetuses with postnuchal fluid had cardiovascular anomalies, VSD with right sided aortic arch and VSD, respectively. The three other fetuses had generalised oedema and effusions without gross postnuchal fluid accumulation, although a fetus with overfolded fingers had a postnuchal bleb. One fetus had cleft lip and palate, meningomyelocele, VSD, and transposition of great arteries, and the last had syndactyly, septum primum atrial septal defect, and a molar placenta.

Eight of these women have had a subsequent successful pregnancy.

\section{INFECTION}

Eleven of our cases had clinical and/or histological findings suggestive of an infective aetiology for the hydropic state. Hydrops was identified prenatally by ultrasound examination in 10 of 11 cases. In seven, this was before 28 weeks of gestation and in four after that time. Seven women were scanned for clinical reasons, one because of raised maternal serum AFP, and two abnormal fetuses were identified during routine scan. Table 1 shows clinical details and scan findings. Both parents of case 7 were of Chinese origin; $\alpha$ thalassaemia was suspected and apparently excluded by the results of haematological investigations. Reinvestigation in a subsequent pregnancy showed that both parents were carriers for $\alpha$ thalassaemia. Three women had normal scans performed before the diagnostic scan. In four cases, ultrasound scan examination showed no fetal heart contractions and two more (cases 8 and 11) died before delivery.
Evidence of infection took the form of round cell infiltration, most readily apparent in the stroma of placental villi, lung parenchyma, and myocardium. Large numbers of circulating nucleated cells were apparent in many organs in four cases and prominent haemopoiesis was observed in placental villous capillaries in four. In three of the former (cases $1,2,7$, and 9 ), intranuclear inclusions were apparent in erythrocyte precursors and macrophages which reacted positively for parvovirus RNA using an in situ hybridisation technique. In case 3 intrauterine death occurred during the course of antibody proven influenzal infection; round cell infiltration was present in placenta, lung, myocardium, and skeletal muscle. The most mature baby in this group (case 11) exhibited a striking frog leg posture after delivery. Skeletal muscle from several sites showed a pattern of groups of fibres of normal size separated by groups of small size fibres and scattered very large fibres. A silver impregnation technique showed regeneration of nerve endings within muscle suggestive of anterior horn cell disease, similar to that in the acute stage of polio virus infection. There was dense cellularity of the lamina propria at several sites in the small intestine and calcification of intestinal contents suggesting previous enteroviral infection.

\section{VISCERAL ANOMALY GROUP}

Seven cases were identified and in six prenata diagnosis of hydrops was made by ultrasound scan (table 1). Four were diagnosed before 28 weeks of gestation. Three cases $(1,6$, and 7$)$ had normal level one scans during the second trimester. Four of these fetuses delivered spontaneously between 27 and 31 weeks of gestation after polyhydramnios and antepartum haemorrhage in three and pre-eclampsia and polyhydramnios in one case. In case 1 , pregnancy was terminated after recognition of anomaly.

The anomalies in this group were diverse. Case 1 had laryngeal atresia with overdistended lungs and a complicated cardiac defect comprising situs inversus, atrial septal defect, double outlet right ventricle, and mitral atresia with a midline abdominal wall defect.

Case 2 had facial dysmorphism and short limbs with curved tibiae which had suggested a prenatal diagnosis of osteogenesis imperfecta. Internal examination showed a large liver and grossly enlarged, cystic kidneys. Histological examination of both showed cystic dysplasia diagnostic of Meckel-Gruber syndrome.

In case 3, a large heart with a small right ventricle was observed on ultrasound scan in addition to hydrops and ascites. Necropsy confirmed cardiomegaly and showed biventricular hypertrophy in an anatomically normal heart. Histological examination of horizontal slices through the ventricular mass showed myocardial hypertrophy at several levels, particularly in the anterior wall of the right ventricle, but also present in the interventricular septum. A pale subendothelial layer was apparent in both ventricles on $\mathrm{H} \& \mathrm{E}$ staining, which comprised 
collagen and elastic fibres, characteristic of subendocardial fibroelastosis.

Case $\mathbf{4}$ had disproportionate ascites and only mild subcutaneous oedema. The lungs were grossly distended and completely filled the chest. The upper airways were patent but histological examination of the lungs showed a paucity of intrapulmonary bronchi with no airways identifiable between lobar bronchi and terminal bronchioles. There were no anomalies in other systems.

In case 5, the only anomaly was a greatly expanded right lobe of the liver which was completely replaced by a vascular hamartoma.

Case 6 also had a vascular anomaly. In addition to fetal hydrops, prominent neck vessels were apparent on ultrasound scan and were sufficiently abnormal to suggest a cervical vascular malformation. Necropsy showed that these vessels were much enlarged but otherwise normal. There was diffuse angiodysplasia of the whole of the cerebral and cerebellar leptomeninges, apparent on naked eye examination as an increase in both size and number of leptomeningeal vessels. This vascular abnormality was confirmed on histological examination.

The last baby in this group was found to be hydropic on ultrasound scan during investigation of extremely large uterine size accompanied by signs of pre-eclampsia. In addition to fetal hydrops and polyhydramnios, hydrocephalus and cerebral haematoma were observed. Necropsy confirmed hydrocephalus and both intraventricular and intracerebral haemorrhage. One portion of the 'haematoma' appeared different; histological examination showed that this was a very vascular primitive neuroectodermal tumour, presumably the source of haemorrhage which had obstructed the aqueduct of Sylvius and caused hydrocephalus. Immunohistochemical staining of the tumour did not show any type of cellular differentiation.

\section{TWINS}

All six cases in this group were products of monochorionic, diamniotic twin gestation (table 1). In five, hydrops was diagnosed prenatally by ultrasound scan. Three had normal scans earlier in pregnancy. Only one of each twin pair was hydropic but four of the nonhydropic twins also died. In five pairs, hydrops was the result of twin-twin transfusion. In the last case there was an acardiac, acephalic cotwin. Two of the hydropic twins and two nonhydropic co-twins who died showed evidence of longstanding ischaemic brain injury. ${ }^{3}$ In one of the latter this was complicated by intracerebral and intraventricular haemorrhage. One hydropic and one non-hydropic twin from different gestations had cardiac ventricular hypertrophy and endocardial fibroelastosis, probably reflecting myocardial ischaemia complicating high output failure.

Five women had successful singleton pregnancies before the index pregnancy. No subsequent pregnancy is, as yet, recorded.
IDIOPATHIC GROUP

Examination of six fetuses showed no pathological abnormality other than hydrops. Four were identified by ultrasound examination during the second trimester. Two were already dead. In two pregnancies second trimester ultrasound scans had been normal.

These six fetuses showed no macroscopic or microscopic evidence of infection and no major visceral anomaly was detected. Three fetuses had a normal karyotype including one $(46, X Y)$ with dysmorphic features of the head and limbs and a septum secundum atrial septal defect. Another fetus had massive postnuchal fluid accumulation but no cardiac defect. Placental or disproportionate hepatic erythropoiesis was not apparent in any case, although nucleated cells were prominent in both fetal and placental vessels in case 3 .

Comparisons between the different diagnostic groups are shown in table 2 . While average maternal age in the chromosome anomaly group was not high, the mean age of women with trisomic 21 and 18 pregnancies was 37 years. Scan diagnosis in this group was made earlier than in other groups, average gestation at diagnosis was 17 weeks in this group, and 19 weeks among fetuses with suspected chromosome anomaly.

Compared with cases of non-immunological hydrops reported previously, ${ }^{2}$ hydrops was diagnosed more frequently while the fetus was still alive, before 20 weeks' gestation, and more frequently associated with chromosome anomaly. A cause or association of fetal hydrops was found more often in the cases reported here $(92 \%)$ compared with $84 \%$ of those investigated between 1976 and 1982 .

\section{Discussion}

The hydropic state results from the combination of a total increase in body water and a relative increase in fluid in the interstitial space. When the latter becomes severe there is usually free fluid in body cavities as well. Maintenance of normal fluid distribution requires a balance of osmotic and hydrostatic forces on either side of cell membranes and an intact sodium pump. The common mechanisms, severe chronic anaemia, fetal heart failure, and obstruction to venous return from the placenta, act through a common pathway at the cellular level of hypoxia but severe hypoproteinaemia may be the starting point of homeostatic failure. ${ }^{4}$

Non-immunological fetal hydrops has come to the fore as a clinical problem as effective prevention and treatment of rhesus hydrops has been widely implemented. A wide range of disorders have been reported in association with non-immune hydrops including a diverse range of malformations, chromosome anomaly, genetic metabolic disease, tumours, and infection, ${ }^{4}$ but when the associations observed in larger series are combined, cardiac and pulmonary malformations, cardiac arrhythmias, chromosome anomalies, and monochorionic twin pregnancy are the commonest associations encountered ${ }^{4}$ In a review of published 
reports of fetal hydrops in the 1980s, Machin noted identification of an associated condition in 80 to $85 \%$ of cases. Only $10 \%$ had abnormal chromosomes. The higher proportion reported here reflects the lower gestation at diagnosis among our cases. Many of the fetuses described here had cardiovascular anomalies. A causal relationship between malformation and hydropic state is put forward by most authors, supported by the in utero demonstration of cardiac arrhythmias in the hydropic fetus with cardiac anomaly ${ }^{67}$ and an excess of complex cardiac lesions with disproportionate representation of ambiguous cardiac situs. ${ }^{26} \mathrm{McF}$ adden and Taylor ${ }^{8}$ caution the uncritical acceptance of such relationships in respect of cardiac malformations, a suggestion which has implications for management of fetal hydrops in the presence of a demonstrated cardiac anomaly.

Interest in the causes, associations, and management of non-immunological hydrops in this unit was stimulated by the resource implications, both to the obstetric and neonatal intensive care units, of delivery by emergency Caesarean section of known hydropic infants when they exhibited signs of fetal distress both before and during labour. These babies required a great deal of medical and surgical attention but their mortality was high. ${ }^{129}$ In 31 of 50 pregnancies described previously, hydrops became apparent in the last trimester of pregnancy. In 13 pregnancies diagnosis was made by ultrasound examination, although in three the fetus was already dead. Since 1982, many changes have taken place in obstetric practice including the frequent recourse to ultrasound scan in the second trimester of pregnancy for a variety of reasons including estimation of gestation, routine fetal anomaly screen, and investigations of intrauterine growth retardation. In future first trimester vaginal scanning might permit very early detection of some hydropic fetuses. ${ }^{10}$ This study was undertaken to examine the causes and associations of fetal hydrops and to compare these with our previous experience to see whether changes in the management of pregnancy resulted in more frequent positive diagnoses or affected the survival of the hydropic fetus.

We drew attention to the difference in associations of fetal hydrops between those fetuses where the hydropic state was diagnosed before 28 weeks' gestation and those where it was observed in the last trimester of pregnancy. ${ }^{2}$ The larger proportion of cases where chromosome anomaly was found or suspected because of a combination of dysmorphic features and structural anomalies reported here reflects the greater number of second trimester diagnoses. It is likely that most of these fetuses would die in utero if termination of pregnancy had not been undertaken after demonstration of an abnormal karyotype.

Eleven of the hydropic fetuses had evidence of infection. The preceding maternal infection usually produces only minor symptoms or may even go unnoticed. The existence of paired sera for antibody studies is unlikely. The advent of techniques, such as in situ hybridisation for identification of viral protein in fixed tissue samples, has already permitted unequivocal diagnosis of parvovirus infection in the hydropic fetus. ${ }^{11}$ The extension of this technique will allow us to characterise other fetal infections fully. Although the parents of case 7 were subsequently shown to be carriers for $\alpha$ thalassaemia, the fetus exhibited round cell infiltration of the myocardium, and both focal villitis and intervillositis were seen in the placenta; the excessive haemopoiesis in the liver and in villous capillaries is compatible with chronic anaemia. We feel therefore that it is likely that the fetus was homozygous for $\alpha$ thalassaemia.

Among the more mature hydropic fetuses, three showed evidence of infection, two had visceral anomaly, two were twins, and two were unexplained. The hydropic state in the only survivor of this group was unexplained. It is in the group of more mature fetuses where careful ultrasound examination of the fetus is particularly important ${ }^{12}$ so that those with major, untreatable malformations can be identified, cardiac arrhythmias sought and treated, or treatment with albumin or blood products given to try to restore normal fluid balance. ${ }^{13}$ When contemplating treatment, it is important that the assessment is thorough and treatment prompt because of the risk of cerebral hypoxic injury. ${ }^{314}$

Most of the associations of fetal hydrops described here have a low risk of recurrence. Occasionally, diagnoses of disorders of known, higher recurrence risk, such as Meckel-Gruber syndrome, infantile arterial calcification, ${ }^{2}$ and some skeletal dysplasias, ${ }^{4}$ are made in association with fetal hydrops. It is most important that the hydropic fetus, whether from termination of pregnancy or spontaneous abortion, is examined with great care so that any association is demonstrated. In most cases, the parents can be confidently, optimistically counselled about prospects for future pregnancies and the unfortunate few prepared for early, appropriate investigations.

We are grateful to Shirley Martin for typing the manuscript.

1 Gough JD, Keeling JW, Castle B, Iliff PJ. The obstetric management of non-immunological hydrops. $\mathrm{Br} \mathcal{f}$ Obstet Gynaecol 1986;93:226-34.

2 Keeling JW, Gough DJ, Iliff P. The pathology of nonrhesus hydrops. Diagn Histopathol 1983;6:89-111.

3 Squier MV, Keeling JW. The incidence of prenatal brain injury. Neuropathol Appl Neurobiol 1991;17:29-38.

4 Keeling JW. Hydrops fetalis and other forms of excess fluid collection in the fetus. In: Wigglesworth JS, Singer DB, eds. Textbook of fetal and perinatal pathology.

5 Machin GA. Hydrops revisited: literature review of 1,414 cases published in the $1980 \mathrm{~s}$. Am $\mathcal{f}$ Med Genet cases published

6 Kleinman CS, Donnerstein RL, DeVore GR, et al. Fetal echocardiography for evaluation of in utero congestive heart failure: a technique for study of nonimmune fetal hydrops. $N$ Engl F Med 1982;306:568-75.

7 Maxwell DJ, Crawford DC, Curry PVM, Tynan MJ, Allan LD. Obstetric importance, diagnosis, and management of LD. Obstetric importance, diagnosis, and

$8 \mathrm{McF}$ adden DE, Taylor GP. Cardiac abnormalities and nonimmune hydrops fetalis: a coincidental, not causal, relationship. Pediatr Pathol 1989;9:11-17.

9 Iliff PJ, Nicholls A, Keeling JW, Gough JD. Non-immunologic hydrops fetalis: a review of 27 cases. Arch Dis Child 1983;58:979-82.

10 Szabó J, Gellén J, Szemere G. Non-immune hydrops in trisomy 18. Diagnosis by vaginosonography and chorion 
villus sampling in the first trimester. Br $\mathcal{F}$ Obstet Gynaecol 1990;97:955-6.

11 Porter HJ, Khong TY, Evans MF, Chan VTW, Fleming KA. Parvovirus as a cause of hydrops fetalis: detection by in situ DNA hybridisation. F Clin Pathol 1988;41:381-3. 12 Watson I, Campbell S. Antenatal evaluation and management in nonimmune hydrops fetalis. Obstet Gynecol 1986;67:589-93.
13 Shimokawa $\mathrm{H}$, Maeda $\mathrm{H}$, Miyamoto $\mathrm{S}$, Koyanagi $\mathrm{T}$, Nakano H. Intrauterine treatment of idiopathic hydrops 14 Kobori JA, Urich H. Intrauterine anoxic brain damage in nonimmune hydrops fetalis. Biol Neonate 1986;49:311-7. 